\title{
보바스개념에 근거한 체간 촉진이 체간정렬과 체중분포에 미치는 효과
}

\author{
장우남, 김중환, 황병용 \\ 용인대학교 보건복지대학 물리치료학과
}

\author{
Effect of Trunk Facilitation based on the Bobath Concept on Trunk Alignment and \\ Weight Distribution in Patients with Stroke \\ Woo-Nam Chang, Jung-hwan Kim, Byong-Yong Hwang* \\ Dept. of Physical Therapy, College of Health Welfare, Yong-In University
}

Purpose The purpose of this study was to investigate the effects of trunk facilitation based on the Bobath concept on trunk alignment and weight distribution on standing in patients with stroke. Methods This study was designed as an assessor-blinded, randomized controlled trial. A total of 27 stroke patients were randomly allocated into the two groups: trunk facilitation group $(n=14)$, and conventional physiotherapy group $(n=13)$. All the patients were trained for 30 minutes a day, 5 times a week for 5 weeks. Results The mean age of the patients in the study group was 50.29 years and that of the control group was 52.54 years. In the results of the trunk alignments, there were significant decreases in spinal length(VP-DM), forward trunk inclination in sagittal plane, trunk imbalance in frontal plane and thoracic angle in the trunk facilitation group $(p<0.05)$. But, there was no difference between the two groups. There were significant increases in backward weight distribution and covered area on affected foot $(p<0.05)$. There was a significant decrease in the forefoot pressure of the unaffected limb in standing $(p<0.05)$. Between the two groups, there were significant difference in the AP weight distribution, covered area on the affected foot, and forefoot pressure on the unaffected foot $(p<0.05)$. Conc/usion The study was demonstrated that the trunk facilitation based on the Bobath concept showed significantly recovery of midline orientation in standing posture.

Key words Bobath concept, stroke rehabilitation, trunk alignment, trunk facilitation, weight distribution

Corresponding author Byong-Yong Hwang (bhwang@yongin.ac.kr)
Received date
Revised date
18 September 2017
Accepted date
21 September 2017
8 October June 2017

\section{I. 서 론}

체간은 우리 신체의 자세조절을 위한 핵심부위로 우리 몸을 항 중력 방향으로 바로 서게 하고 동시에 주어진 과제와 환경 변 화에 신속히 적응할 수 있도록 돕는다. ${ }^{1)}$ 하지만, 뇌졸중으로 인해 편마비가 발생한 환자는 체간의 감각, 운동기능 손상으로 자세와 동작수행에 문제를 갖게 된다. ${ }^{2-5)}$ 일반적으로 뇌졸중으 로 인해 편마비가 발생한 경우 마비측 상하지의 뚜렷한 근약화 를 나타내지만, 체간은 손상위치 및 기능적인 변화를 특정하기 어려운 다각적인 영향을 받게 되는 것이 특징이다. ${ }^{6-7)}$ 자세와 동작 조절의 문제가 발생하는 뇌졸중 환자에 있어서 체간조절 능력은 기능회복에 중요한 척도가 된다. ${ }^{3)}$

체간은 신체부위 간의 상호작용을 통해 자세조절 및 독립

doi : http:dx.doi.org/10.17817/2017.09.20.111191
적인 기능을 수행하는 핵심조절점(key points of control) 또 는 기능적 단위(functional units)중 하나이다. ${ }^{8-9)}$ 핵심조절점 은 흥추의 중간부위를 중앙핵심조절점, 어깨, 머리 및 골반을 근위핵심조절점, 손과 발을 원위핵심조절점이다. 그 중 중앙핵 심조절점은 시상면, 관상면과 수평면의 세 면에서 이루어지는 체간동작을 통해서 체중이동과 신체 좌우의 상호작용을 가능하 게 한다. ${ }^{10)}$ 체간근은 서로 균형을 이루어 척주를 선택적이고 분절화된 신전이 가능하도록 하며, 상.하지의 동작을 자유롭게 할 수 있도록 돕는다. ${ }^{11)}$

보바스 치료를 포함한 대부분의 편마비 환자를 대상으로 이 루어지는 물리치료의 가장 핵심적인 목표는 체간의 안정성을 강 화하는 것이다. 이를 통해서 섬세한 체간조절과 정확한 체중이 동 능력을 강화시키며, 동시에 손과 발의 기능적 효과기의 역할 을 수행하도록 할 수 있다. ${ }^{12)}$ 체간조절 능력강화는 체간과 다른 
신체분절 간의 동적 안정성을 위한 상호작용이 가장 중요한 목 적이다. 즉, 머리의 위치와 방향, 상하지의 과제지향적 동작패턴 은 직접적으로 체간을 포함한 근위부의 안정성과 관련된다. ${ }^{13)}$

Mudie 등 $(2002)^{14)}$ 은 보바스개념에 근거한 체간운동치료 접근법, 과제 지향적 잡기패턴 훈련과 피드백을 이용한 균형훈 련의 효과를 비교를 하였다. 다른 방법들과 비교해 보바스개념 에 근거한 방법이 단기간 내에 대칭적인 균형을 위한 체간조절 에 효과적이라고 보고하였다. 반면, Pollock 등(2002) ${ }^{15)}$ 의 연 구에서는 자세균형 향상을 목표로 4주간 보바스개념을 기반으 로 한 물리치료를 시행하였지만, 앉은 자세, 선 자세, 일어서고 앉기와 팔뻗기 동작 시 자세균형의 대칭성 검사에서 집단 간의 차이를 발견하지 못했다고 보고하였다. 체간가동범위 운동치료 는 체간의 외측굴곡운동의 증가를 나타냈지만, 더 효과적인 체 간 조절을 위해서는 기능적 활동에 기반을 둔 운동치료가 필요 하다고 하였다. ${ }^{16)}$ Karthikbabu 등(2011a) ${ }^{17)}$ 은 과제지향적 체 간운동치료를 위해서 안정된 치료대 위에서 시행한 경우와 불 안정한 짐볼 위에서 시행한 경우를 분석하였다. 결과는 불안정 한 기저면인 짐볼을 사용한 경우가 체간조절 향상에 효과가 있 었다고 하였다. Karthikbabu 등 ${ }^{18)}$ 의 또 다른 연구에서 보바 스개념을 바탕으로 한 체간훈련이 보행속도, 박자, 대칭적 보행 향상에 영향을 미친다고 보고하였고, Saeys 등 $(2012)^{19)}$ 은 무 작위 임상연구를 통해서 일반적인 물리치료에 체간훈련을 추가 한 결과 체간조절, 균형과 기능 활동에 긍정적인 효과가 있었 다고 하였다. 2016년에 Kilinc 등 ${ }^{20)}$ 은 보바스개념의 개별적 문제해결 접근법을 사용한 체간조절 치료가 일반적인 물리치료 와 비교해 체간조절, 균형과 보행능력 향상에 효과가 있었다고 하였다.

현재까지 연구는 뇌졸중으로 인한 편마비 환자의 체간기능 의 향상을 위한 목적으로 체간근력과 안정성 향상, 체간 가동
범위 증가, 정적 또는 동적 체간 균형조절과 보행 등을 기초로 하고 있다. 편마비 환자의 체간 조절의 중요성을 강조하고 있 음에도 불구하고, 뇌졸중 후 편마비 환자에게 나타나는 체간정 렬과 대칭적 자세 간의 상호관계는 분명하게 설명하지 못하고 있다. 따라서, 본 연구는 뇌졸중으로 인해 편마비 환자를 대상 으로 보바스개념에 근거한 체간 촉진이 체간정렬과 체중분포의 대칭성에 미치는 효과를 규명하고자 한다.

\section{II. 연구 방법}

\section{1. 연구 대상자}

본 연구는 뇌졸중으로 진단받고 재활전문기관인 $\mathrm{K}$ 병원에 입원 치료 중인 환자를 대상으로 하였으며, 일상생활 자립도가 중등 도 이상인 27 명이었다. 선정 기준은 첫째, 뇌졸중으로 인해 편 마비가 발생한 환자 중 발병 후 6 개월이 경과한 환자, 둘째, 의학적으로 안정된 상태이며, 연구에 필요한 내용을 이해하고 지시한 내용을 수행할 수 있는 환자한글판 간이정신상태검사 24 점 이상인 자), 셋째, 지팡이나 보조기 없이 10미터 이상 독 립보행이 가능한 환자로 하였다. 제외 기준은 첫째, 척추와 하 지의 정형외과 질환이 있는 환자, 둘째, 심혈관질환 및 내과질 환으로 약물을 복용하거나 조절 중인 환자로 하였다(Table 1).

\section{2. 연구 설계 및 절차}

본 연구는 두 집단 사전-사후 평가 설계로 측정자 단일맹검법 으로 하였다. 연구 집단은 중재 방법에 따라 보바스개념에 근 거한 체간 촉진군과 일반 물리치료군으로 무작위 선출하여 두 군으로 나누었다. 두 군은 모두 하루에 30 분씩 1 회, 주당 5 회 총 5 주간 치료를 시행하였다.

Table 1. The general and clinical characteristics of the subjects

\begin{tabular}{|c|c|c|c|c|}
\hline Variables & $\begin{array}{l}\text { Study } \\
\text { (n=14) }\end{array}$ & $\begin{array}{l}\text { Control } \\
\text { (n=13) }\end{array}$ & $x^{2} / t$ & $\mathrm{p}$ \\
\hline Gender (M/F, \%) & $10 / 4(71 / 29)$ & $9 / 4(69 / 31)$ & 0.02 & 0.90 \\
\hline Age (years) & $50.29 \pm 5.89^{\mathrm{a}}$ & $52.54 \pm 5.61$ & -1.02 & 0.32 \\
\hline Height $(\mathrm{cm})$ & $168.00 \pm 6.53$ & $167.69 \pm 7.93$ & 0.11 & 0.92 \\
\hline Weight (kg) & $67.71 \pm 8.33$ & $71.00 \pm 7.43$ & -1.08 & 0.29 \\
\hline Hemor/Infar (\%) & $5 / 9(36 / 64)$ & $8 / 5(62 / 39)$ & 1.80 & 0.18 \\
\hline Hemi-side (R/L, \%) & $7 / 7(50 / 50)$ & 5/8 (39/61) & 0.36 & 0.55 \\
\hline Duration (month) & $10.50 \pm 2.96$ & $11.08 \pm 2.75$ & -0.53 & 0.61 \\
\hline MBI (score) & $74.00 \pm 6.88$ & $67.62 \pm 11.33$ & 1.78 & 0.09 \\
\hline 10MW (sec) & $30.87 \pm 8.10$ & $25.08 \pm 11.57$ & 1.56 & 0.14 \\
\hline
\end{tabular}

Note. Hemor: hemorrhage, Infar: infarction, MBI: Modified Bathel Index, 10MW: 10 Meter Walk test. ${ }^{a}$ mean \pm standard deviation. 


\section{3. 중재 방법}

본 연구의 체간 촉진법의 목적은 하지의 근 활성화와 정렬을 통한 안정된 기저면 위에 몸통과 골반의 분절적이면서 협력적 인 신전상태의 회복과 신체 무게중심을 상방으로 끌어올려주는 상승력(rising force) 강화이다. ${ }^{10)}$

첫번째, 사전 준비단계(Make possible)로 보상전략 감소 를 위한 신체 좌우의 구심성 정보 통합 능력 증진이다. 이 단 계는 자세 적응력 향상을 위해 손과 지면의 접촉 능력 활성화 와 흥추부의 신전 촉진을 통해서 체간 및 사지의 보상전략을 최소화 시키는 것이다. 두번째 단계는 동작조성단계(Make Necessary)이다. 이 단계에서는 흥부의 신전 촉진을 통한 골 반과 몸통의 항중력 활동의 최대 강화가 목표이며, 골반과 엉 덩관절 전후와 측방으로 항중력 활동 촉진, 체간의 최대신전을 위한 중앙핵심조절부(흥부) 촉진과 체간의 수평선상에서 수직 선상으로 신근활동 강화하는 것이다. 마지막 세번째 단계는 동 작실행단계(Let it happen)로 안정성 한계의 범위확장이 목표 이며, 강화된 체간신근을 기반으로 앉은 자세에서 일어서기 동 작패턴 강화와 체간근 활동을 선 자세에서 유지 및 강화하는 것이다.

대조군은 체간가동범위 증가를 위한 신장운동과 근력강화 훈련을 포함한 기능훈련을 반복적으로 실시한다. 물리치료의 진행은 누운 자세에서 매트운동을 시작으로 교각훈련(bridging), 옆구르기 훈련(rolling over), 일어나 앉기 훈련, 앉은 자세에 서 일어서기와 선 자세에서 앉기를 반복 훈련한다. 치료의 마 지막은 보행훈련으로 마친다.

\section{4. 측정도구와 자료수집}

\section{1) 체간정렬 및 체중분배율 측정}

척추정렬 측정은 래스터입체촬영(rasterstereography) 방식인 3차원 척추진단영상기(ABW-MED version 3, $\mathrm{ABW} \mathrm{GmbH}$ Co., 독일)를 사용하였다(Figure 1-A) 래스터입체촬영을 사용 한 장비는 주사선군의 패턴을 표시영역에 고르게 덮도록 하여 주사선의 패턴을 영상으로 척추형태를 재현하는 방식이다. ${ }^{21)}$ 표식자는 검사자 한 명이 부착하였으며, 부착부위는 경추 7 번, 양쪽 견갑골 상각과 하각, 요추오목(lumbar dimple), 천골 중앙(center of sacrum)으로 총 8개의 표식자를 사용하였다. 촬영시간은 0.04 초의 짧은 시간에 이루어지며 촬영된 영상은 컴퓨터에 저장되어 $\mathrm{ABW}-\mathrm{MED}$ 소프트웨어를 사용하여 분석할 수 있다. 분석은 척주길이, 체간 기울기, 흉추각도, 요추각도, 척주만곡, 척추 외측편위, 척추회전 각도를 하였다.

\section{2) 체중분배율 및 족저압 측정}

체중분배율 및 족저압 변화를 측정하기 위해 DIERS pedoscan (DIERS International $\mathrm{GmbH}$, Schlangenbad, 독일) 장비

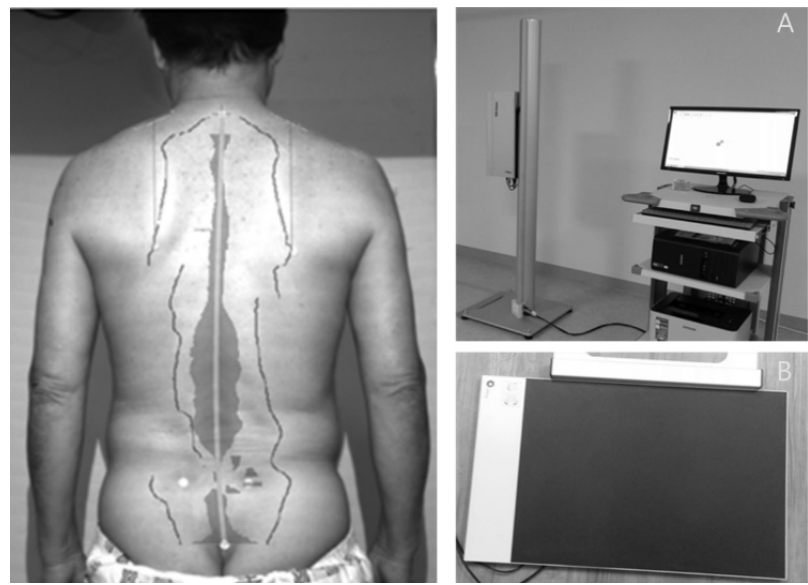

Figure 1. Measurement of spinal alignment by using $A B W-M E D(A)$ and weight distribution, DIERS pedoscan(B).

를 사용하였다. 편마비 환자의 마비측과 비마비측의 체중분배 율과 족저압 차이를 척추정렬 측정을 위한 선 자세에서 $\mathrm{ABW}-\mathrm{MED}$ 와 동기화하여 동시에 측정하였다.(Figure 1-B)

좌우측 체중분배율 값은 비마비측 체중분배율에서 마비측 을 뺀 값으로 기록하였으며, 전후방 체중분배율 은 후방 체중 분배율 값에서 전방 값을 뺀 것으로 기록하였다.

\section{5. 분석방법}

본 연구의 모든 통계는 SPSS version 18 을 이용하여 평균과 표준편차를 산출하였다. 대상자의 일반적 특성은 기술통계를 사용하였고, 집단 간의 차이를 알아보고 위해 카이제곱 검정과 독립 $t$ 검정을 실시하였다. 두 집단의 체간 정렬, 체중분배율 및 족저압의 사전, 사후 측정값의 비교를 위해서 비모수 검정 법을 사용하여 분석하였다(집단간: Mann-Whitney test; 집단 내: Wilcoxon's signed-ranks test). 자료의 모든 통계적 유 의수준(a)은 0.05 로 하였다.

\section{III. 결 과}

\section{1. 체간정렬 변화}

1) 체간의 길이 변화

경추에서 요추오목까지의 거리변화는 체간촉진 치료 후 감소된 결과를 얻었으나 $(\mathrm{p}<0.05)$, 경추에서 천골중앙까지 측정한 값 에서는 변화가 없었다 $(\mathrm{p}>0.05)$.

\section{2) 체간 기울기 변화}

시상면에서 체간 전방기울기는 체간촉진 치료 후 유의하게 감 소된 결과를 나타냈으며 $(\mathrm{p}<0.05)$, 관상면의 체간 불균형 
(trunk imbalance)각도도 감소된 결과를 보였다 $(\mathrm{p}<0.05)$.

\section{3) 척추각도 변화}

흥추각도(thoracic angle)는 체간촉진 치료 후 감소된 결과로 흥추 신전의 증가를 보였으며( $\mathrm{p}<0.05)$, 요추각도(lumbar angle)는 변화가 없었다 $(\mathrm{p}>0.05)$. 대조군의 경우 치료 후 요 추각도의 증가가 나타났다 $(\mathrm{p}>0.05)($ Table 2$)$.

\section{2. 치료 전, 후 체중분배율과 족저압 변화}

체중분배율과 족저압변화에 대한 치료 전후의 결과는 내외측 체중분배율, 전·후 체중분배율, 족저압, 발 접촉면적 등의 변화 량을 분석하였다.

\section{1) 내외측 체중분배율 변화}

내외측 체중분배율 변화는 체간촉진 치료후 비대칭분포가 평균 적으로 감소를 보였으나, 통계적으로 유의하지 않았다 ( $\mathrm{p}>0.05)$. 대조군은 비대칭체중분포의 통계적으로 유의한 감 소결과가 나타났다 $(\mathrm{p}<0.05)$.

\section{2) 전후방 체중분배율 변화}

전·후방 체중분배율 변화는 체간촉진 치료 후 통계적으로 유의 한 후방이동이 나타났다 $(\mathrm{p}<0.01)$, 마비측과 비마비측의 전·후 방 체중분배율은 마비측 $(\mathrm{p}>0.05)$ 과 비마비측 $(\mathrm{p}<0.05)$ 모두 후방으로 증가한 것으로 분석되었다. 전·후방 체중분포 결과는 연구군과 대조군의 집단 간 유의한 차이를 보였다 $(\mathrm{p}<0.05)$.

\section{3) 족저압 변화}

족저압은 마비측과 비마비측 발의 전·후방의 족저압을 구분하 여 평균값을 분석하였다. 마비측 발의 전방 족저압 결과에서 연구군과 대조군 모두 통계적으로 유의한 차이를 보이지 않았 으나, 연구군의 비마비측 전방 족저압의 결과에서 유의한 감소 가 나타났다 $(\mathrm{p}<0.05)$. 족저압의 결과에서 비마비측의 전방 족 저압 변화가 두 군간 유의한 차이가 나타났다 $(\mathrm{p}<0.05)$.

\section{4) 접촉면 변화}

마비측과 비마비측 발의 접촉면적 변화결과에서 연구군의 마비 측 발은 치료 후 통계적으로 유의한 접촉면적 증가를 보였으며 $(\mathrm{p}<0.05)$, 비마비측 발도 증가를 보였으나, 통계적으로 유의하 지는 않았다 $(\mathrm{p}>0.05)$. 발 접촉면적에서 두 집단의 유의한 차 이가 나타났다 $(\mathrm{p}<0.05)($ Table 3$)$.

\section{IV. 고 찰}

본 연구는 뇌졸중으로 인해 편마비가 발생한 환자를 대상으로 보바스개념에 근거한 체간 촉진의 효과를 알아보고자 실시하였 다. 보바스개념에 근거한 체간 촉진에 대한 체간정렬 변화는 집단 내에서는 의미 있는 차이를 나타냈지만, 집단 간 의미 있 는 차이는 없었다. 척주길이 변화는 경추7번에서 요추오목까지 길이 변화에서 치료 후 유의한 감소가 나타났으며 $(\mathrm{p}<0.05)$, 흥추각도의 감소와 체간 전방기울기의 감소가 나타났다. 이와 같은 결과는 경추 7 번 부위의 후방이동을 보인 것이다. 이것은 체간촉진 치료가 척추의 중립위치의 회복에 영향을 미쳤다는 것으로 설명할 수 있다. 본 연구와 동일한 장비로 척주정렬 측

Table 2. Pre-post comparison on spinal alignments

\begin{tabular}{|c|c|c|c|c|c|c|c|}
\hline \multirow[b]{2}{*}{ Variables } & \multicolumn{3}{|c|}{ Study ( $n=14$ ) } & \multicolumn{3}{|c|}{ Control ( $n=13$ ) } & \multirow[b]{2}{*}{$p$} \\
\hline & pre & post & $\begin{array}{l}\text { Change } \\
\text { (post-pre) }\end{array}$ & pre & post & $\begin{array}{l}\text { Change } \\
\text { (post-pre) }\end{array}$ & \\
\hline Length(VP-DM)(mm) & $474.21 \pm 22.93$ & $466.07 \pm 24.60$ & $-8.14 \pm 13.07^{*}$ & $478.54 \pm 32.74$ & $474.54 \pm 37.62$ & $-4.00 \pm 12.88$ & 0.49 \\
\hline Length(VP-SP)(mm) & $525.29 \pm 39.99$ & $522.00 \pm 43.32$ & $-3.29 \pm 16.55$ & $536.77 \pm 45.34$ & $541.23 \pm 46.45$ & $4.46 \pm 15.41$ & 0.28 \\
\hline $\operatorname{Tr}-\operatorname{Inc}\left(^{\circ}\right)$ & $3.14 \pm 2.35$ & $1.64 \pm 1.39$ & $-1.50 \pm 1.83^{* * *}$ & $4.85 \pm 3.78$ & $4.08 \pm 2.84$ & $-0.77 \pm 1.92$ & 0.65 \\
\hline $\operatorname{Tr}-\operatorname{Imb}\left(^{\circ}\right)$ & $1.50 \pm 1.40$ & $0.71 \pm 0.61$ & $-0.79 \pm 1.25^{*}$ & $2.15 \pm 1.99$ & $2.38 \pm 1.71$ & $0.23 \pm 1.30$ & 0.07 \\
\hline T-Angle $\left(^{\circ}\right)$ & $14.14 \pm 2.63$ & $13.00 \pm 2.63$ & $-1.14 \pm 1.79^{*}$ & $14.23 \pm 4.23$ & $14.31 \pm 4.35$ & $0.08 \pm 2.43$ & 0.22 \\
\hline L-Angle $\left(^{\circ}\right)$ & $9.64 \pm 2.65$ & $9.64 \pm 1.99$ & $0.00 \pm 1.52$ & $7.92 \pm 2.53$ & $8.69 \pm 2.18$ & $0.76 \pm 1.01^{*}$ & 0.07 \\
\hline $\mathrm{KA}\left({ }^{\circ}\right)$ & $46.21 \pm 8.21$ & $45.71 \pm 8.28$ & $-0.50 \pm 4.00$ & $45.92 \pm 10.36$ & $47.08 \pm 7.42$ & $1.15 \pm 4.60$ & 0.24 \\
\hline $\mathrm{LA}\left({ }^{\circ}\right)$ & $30.79 \pm 8.90$ & $31.29 \pm 6.39$ & $0.50 \pm 4.18$ & $27.54 \pm 9.09$ & $27.92 \pm 9.70$ & $0.38 \pm 2.96$ & 0.83 \\
\hline
\end{tabular}

${ }^{*} p<0.05,{ }^{* *} p<0.01,{ }^{* * *} p<0.001$

Note. VP: vertebra prominens, DM: lumbar dimple, SP: sacrum point, Tr-Inc: trunk inclination, Tr-Imb: trunk imbalance, T-angle: thoracic angle, L-angle: lumbar angle, KA: kyphosis angle, LA: lordosis angle, ${ }^{a}$ mean \pm standard deviation. 
Table 3. Pre-post comparison on weight distributions \& foot pressures

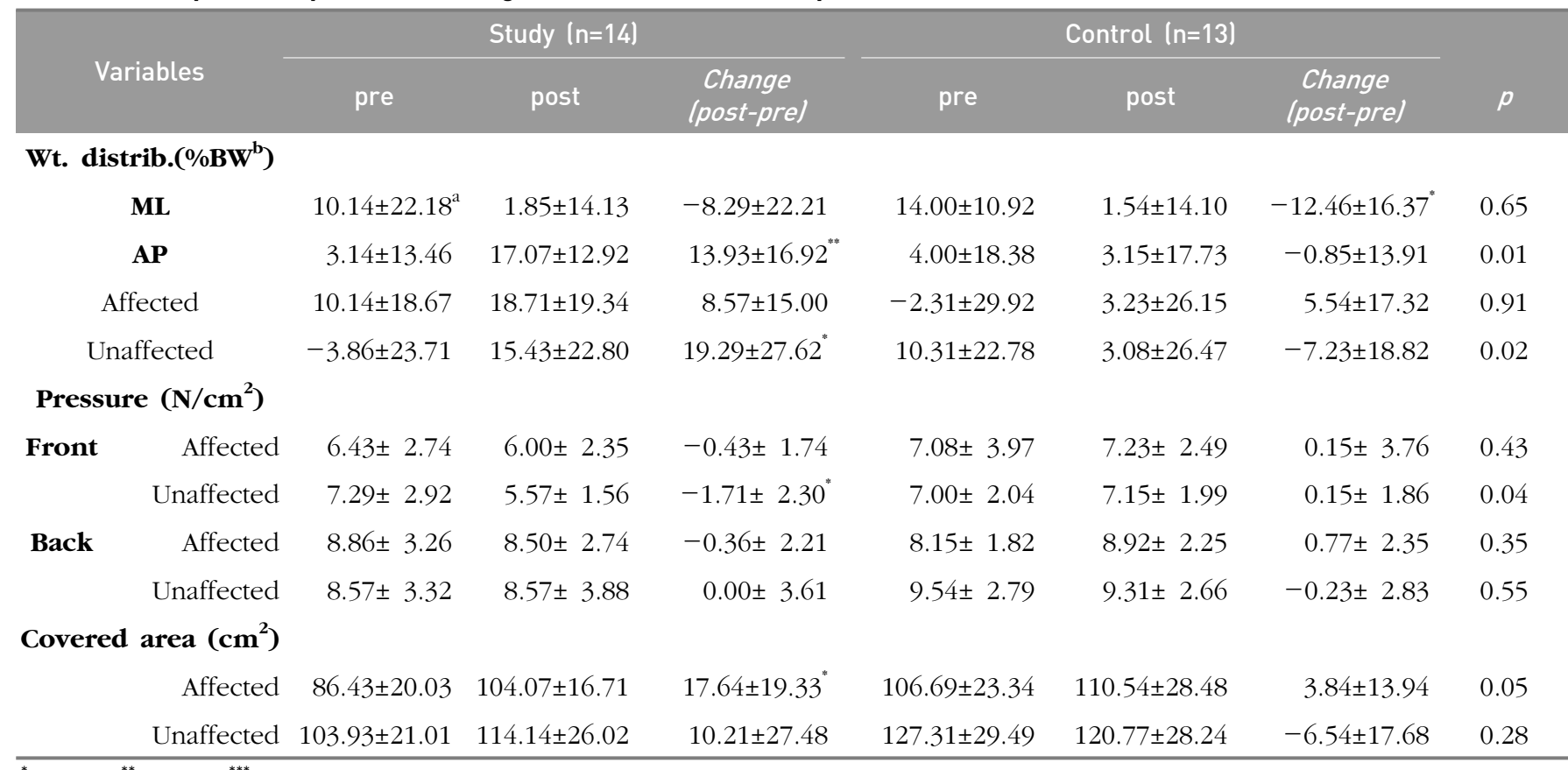

${ }^{*} p<0.05,{ }^{* *} p<0.01,{ }^{* * *} p<0.001$

Note. Wt. distrib.: weight distribution, ML: Mediolateral distribution, AP: anteroposterior distribution, negative (-): affected and forward weight distribution, positive $(+)$ : unaffected and backward weight distribution; ${ }^{a}$ mean \pm standard deviation, ${ }^{b} \%$ body weight.

정에 대한 신뢰도와 타당도 연구를 한 $\mathrm{Yi}$ 등 $(2016)^{22)}$ 의 결과 에 의하면 체간기울기 각도가 $-1.65 \pm 1.57$ 의 평균값을 보였으 며, 연구 대상자인 뇌졸중 환자는 정상인과 비교해서 체간기울 기가 전방으로 증가된 상태라는 것을 보고하였다. Keifer (1997)등 ${ }^{23)}$ 은 흥추1번의 전방위치변화에 따른 척추에 주어지 는 축하중의 증가와 근 활성도의 변화에 관한 보고를 하였다. 흥추1번의 중립위치 회복은 척추분절의 안정성과 척추 안정화 를 강화시키는 핵심안정근 활성화를 강화한다고 하였다. ${ }^{24)}$ 따 라서 보바스개념에 근거한 체간촉진 치료는 체간의 중립위치 회복을 통해서 척추분절간 안정성과 핵심안정근 강화에 영향을 줄 수 있다고 할 수 있다.

자세 안정성의 향상은 뇌졸중 후 재활을 위한 중요한 목표 이다. 특히, 비마비측 하지의 체중부하 비대칭이 뇌졸중 후 편 마비 환자에게는 일반적이므로, 체중부하의 대칭적 회복은 뇌 졸중 후 균형향상과 기능적 활동을 위한 중요한 목표가 된 다. ${ }^{25)}$ 본 연구의 결과에서 체간 촉진 후 전·후방 체중분배율이 후방으로 증가한 것으로 나타났으며 $(p<0.01)$, 뿐만 아니라 집 단 간에도 유의한 차이를 보였다 $(p<0.05)$. 하지만 좌우 체중분 포의 대칭성 회복은 집단간 유의한 차이가 없었다. 이것은 보 바스개념에 근거한 체간촉진과 일반적인 물리치료 방법이 좌우 체중분포의 대칭성 회복에 대해서는 긍정적인 변화를 제공할 수 있다는 것을 의미한다. 하지만 후방 체중분포의 증가는 보
바스개념에 근거한 체간 촉진을 통해서 얻을 수 있다고 판단할 수 있을 것이다. Van Asseldonk 등 $(2006)^{26)}$ 은 뇌졸중 환자 를 대상으로 체중분배율과 균형의 관련성을 연구하였다. 비마 비측의 체중분배율의 평균값은 체중의 $40 ~ 45 \%$ 인 경우가 $10 ~ 20 \%$ 의 체중분배율을 보인 경우보다 동적 균형에 더 많은 기여를 하는 것을 확인하였다. 체중분배율 변화와 더불어 비마 비측 발의 전방 족저압의 감소와 마비측 발의 접촉면의 의미 있는 증가로 보바스개념에 근거한 체간 촉진의 치료목적에 부 합하는 항중력 신전의 효과가 있었다고 판단한다.

이상의 결과는 보바스개념에 근거한 체간 촉진 치료가 선 자세에서 체간 길이 감소, 체간 전·후, 좌우 기울기, 흥추각도 의 감소에 효과가 있으며, 후방 체중분포를 증가시킴으로써 체 간의 중립위치 회복과 항중력 신전의 향상에 효과가 있는 것으 로 판단할 수 있다.

\section{V. 결론 및 제언}

보바스개념에 근거한 체간 촉진법은 안정적인 기저면을 확보하 여 체간과 골반의 분절적이면서 협력적인 신전 회복과 신체의 무게중심을 높여 항중력 상승력을 강화하는데 있다. 본 연구의 결과를 통해서 보바스개념에 근거한 체간 촉진 치료가 체간의 
수직자세 회복과 신전을 증가시킴으로써 체간의 중립위치 회복 과 항중력 신전의 향상에 효과가 있다는 것을 규명하였다. 향후에는 연구 결과의 일반화를 위하여 보다 많은 대상자들의 참여가 필요할 것이며, 체간 촉진에 대한 구조적인 측면과 더 불어 운동조절 기전의 명확한 규명을 위해서 더욱 세분화된 치 료 목적과 방법을 적용하는 것이 필요할 것이다.

\section{References}

1. Verheyden G, Nieuwboer A, Mertin J, et al. The Trunk Impairment Scale: A new tool to measure motor impairment of the trunk after stroke. Clin Rehabil. 2004;18(3):326-41.

2. Ryerson S, Byl NN, Brown DA, et al. Altered trunk position sense and its relation to balance functions in people post-stroke. J Neurol Phys Ther. 2008;32(1) :14-20.

3. Verheyden G, Nieuwboer A, Feys H, et al. Discriminant ability of the Trunk Impairment Scale: A comparison between stroke patients and healthy individuals. J Disabil Rehabil. 2005;27(17):1023-8.

4. Karatas M, Cetin N, Bayramoglu M, et al. Trunk muscle strength in relation to balance and functional disability in unihemispheric stroke patients. Am J Phys Med Rehabil. 2004;83(2):81-7.

5. Hsieh CL, Sheu CF, Hsueh IP, et al. Trunk control as an early predictor of comprehensive activities of daily living function in stroke patients. Stroke. 2002;33(11): 2626-30

6. Tsuji T, Liu M, Hase $\mathrm{K}$, et al. Trunk muscles in persons with hemiparetic stroke evaluated with computed tomography. J Rehabil Med. 2003;35(4):184-8.

7. Fujiwara T, Sonoda S, Okajima Y, et al. The relationships between trunk function and the findings of transcranial magnetic stimulation among patients with stroke. J Rehabil Med. 2001;33(6):249-55.

8. Bobath B. Adult Hemiplegia: Evaluation and Treatment. Heinemann Medical Books, Oxford. 1990.

9. Kidd G, Lawes N, Musa I. Understanding Neuromuscular Plasticity. London, Edward Arnold. 1992.

10. Gjelsvik BE. The Bobath concept in Adult Neurology. Georg Thieme Verlag, Germany. 2008.

11. Hodges PW, Richardson CA. Contraction of the abdominal muscles associated with movement of the lower limb. Phys Ther. 1997;77(2):132-42.

12. Edwards S. Neurological Physiotherapy: A Problem- solving Approach. Churchill Livingstone. 1996.

13. Cabanas-Valdes R, Cuchi GU, Bagur-Calafat C. Trunk training exercises approaches for improving trunk performance and functional sitting balance in patients with stroke: a systematic review. NeuroRehabil. 2013;33(4):575-92.

14. Mudie MH, Winzeler-Mercay U, Radwan S, et al. Training symmetry of weight distribution after stroke: A randomized controlled pilot study comparing task-related reach, Bobath and feedback training approaches. Clin Rehabil. 2002;16(6):582-92.

15. Pollock AS, Durward BR, Rowe PJ, et al. The effect of independent practice of motor tasks by stroke patients: a pilot randomized controlled trial. Clin Rehabil. 2002;16(5):473-80.

16. Verheyden G, Vereeck L, Truijen S, et al. Additional exercises improve trunk performance after stroke: A pilot randomized controlled trial. Neurorehabil Neural Repair. 2009;23(3):281-6.

17. Karthikbabu S, Bhamini K, Manikandan N, et al. Role of trunk rehabilitation on trunk control, balance and gait in patients with chronic stroke: A pre-post design, Neurosci Med. 2011a; 2:61-7.

18. Karthikbabu S, Nayak A, Vijayakumar K, et al. Comparison of physio ball and plinth trunk exercises regimens on trunk control and functional balance in patients with acute stroke: a pilot randomized controlled trial. Clin Rehabil. 2011b;25(8):709-19.

19. Saeys W, Vereeck L, Truijen S, et al. Randomized controlled trial of truncal exercises early after stroke to improve balance and mobility. Neurorehabil Neural Repair. 2012;26(3):231-8.

20. Kilinc M, Avcu F, Onursal O, et al. The effects of Bobath-based trunk exercises on trunk control, functional capacity, balance, and gait: a pilot randomized controlled trial. Top Stroke Rehabil. 2016;23(1):50-8.

21. Drerup B, Hierholzer E. Back shape measurement using video rasterstereography and three-dimensional reconstruction of spinal shape. Clin Biomech. 1994;9(1): 28-36.

22. Yi YS, Yoo SK, Lee DG, et al. Reliability and validity of rasterstereography measurement for spinal alignment in healthy subjects. Phys Ther Rehabil Sci. 2016;5(1):22-8.

23. Kiefer A, Shirazi-Adl A, Parnianpour M. Stability of the human spine in neutral postures. Eur Spine J. 
1997;6:45-53.

24. Bernhardt M, Bridwell KH. Segmental analysis of the sagittal plane alignment of the normal thoracic and lumbar spines and thoracolumbar junction. Spine. 1989;14(7): 717-21.

25. Kamphuis JF, de Kam D, Geurts AC, et al. Is weight-bearing asymmetry associated with postural instability after stroke? A systematic review. Stroke Res Treat. 2013:1-13.

26. van Asseldonk EH, Buurke JH, Bloem BR, et al. Disentangling the contribution of the paretic and non-paretic ankle to balance control in stroke patients. Exp Neurol. 2006;201(2):441-51. 
